\title{
GLOBAL PRECIPITATION AT ONE-DEGREE DAILY RESOLUTION FROM MULTI-SATELLITE OBSERVATIONS
}

George J. Huffman ${ }^{1,2}$, Robert F. Adler ${ }^{1}$, Mark M. Morrissey ${ }^{3}$, Scott Curtis ${ }^{1,4}$, Robert Joyce ${ }^{5}$, Brad McGavock $^{3}$, Joel Susskind ${ }^{1}$

$1:$ NASA/GSFC Laboratory for Atmospheres, Greenbelt, MD

2: Science Systems and Applications, Inc., Lanham, MD

3: Environmental Verification and Analysis Center, Norman, OK

4: Joint Center for Earth-System Technology, Baltimore, MD

5: Climate Prediction Center, NCEP/NWS/NOAA, Washington, DC;

Research and Data Corp., Greenbelt, MD

Submitted to Journal of Hydrometeorology

1 April 2000

Corresponding author Address: Dr. George J. Huffman/SSAI, NASA/GSFC Code 912 , Greenbelt, MD 20771. 


\title{
Global Precipitation at One-Degree Daily Resolution From Multi-Satellite Observations
}

\begin{abstract}
The One-Degree Daily (1DD) technique is described for producing globally complete daily estimates of precipitation on a $1^{\circ} \times 1^{\circ}$ lat/long grid from currently available observational data. Where possible $\left(40^{\circ} \mathrm{N}-40^{\circ} \mathrm{S}\right)$, the Threshold-Matched Precipitation Index (TMPI) provides precipitation estimates in which the 3-hourly infrared brightness temperatures (IR $T_{b}$ ) are thresholded and all "cold" pixels are given a single precipitation rate. This approach is an adaptation of the Geostationary Operational Environmental Satellite (GOES) Precipitation Index (GPI), but for the TMPI the IR $\mathrm{T}_{\mathrm{b}}$ threshold and conditional rain rate are set locally by month from Special Sensor Microwave/Imager (SSM/I)-based precipitation frequency and the Global Precipitation Climatology Project (GPCP) satellite-gauge (SG) combined monthly precipitation estimate, respectively. At higher latitudes the 1DD features a rescaled daily Television Infrared Observation Satellite (TIROS) Operational Vertical Sounder (TOVS) precipitation. The frequency of rain days in the TOVS is scaled down to match that in the TMPI at the data boundaries, and the resulting non-zero TOVS values are scaled locally to sum to the SG (which is a globally complete monthly product). The time series of the daily $1 D D$ global images shows good continuity in time and across the data boundaries. Various examples are shown to illustrate uses. Yalidation for individual grid box values shows a very high root-mean-square errer, but it improves quickly when users perform time/space averaging according to their own requirements.
\end{abstract}

\section{Introduction}

A long time series of fine-scale observation-based global precipitation is needed to support a variety of studies, including global change, surface hydrology, and numerical weather and climate model initialization and validation. However, data record, sampling, and algorithmic considerations limit the range of scales that could be reported with reasonable accuracy. For example, the World Climate Research Program (WCRP) established the Global Precipitation Climatology Project (GPCP) with the initial goal of producing precipitation estimates on a monthly $2.5^{\circ} \times 2.5^{\circ}$ lat/long grid for a number of years (WCRP, 1986). The GPCP is succeeding in this goal, with over a decade of data available (1986-1999 at present), another seven years in preparation (1979-1985), and routine production continuing a few months after real time.

Due to the lack of finer scale precipitation data numerous applications remain stymied. Researchers wish to validate hydrologic stream flow models by forcing them with observed data that resolve individual storms and catch basins. Even monthly-scale events are hard to study with calendar-month averages. Extratropical blocking events are a typical example. They initiate and decay within the span of a few days, but can persist for weeks (Blackmon et al. 1984). Calendar-month averages typically mix blocking and non-blocking periods, whereas daily data allow the researcher to composite the data much more cleanly.

The fundamental barrier to finer-scale estimates is the lack of accurate, dense global data, either from in-situ or remote sensors. Some regions do have the possibility of detailed precipitation estimates thanks to local networks of sensors, such as the WSR-88D radar system in the United States (Crum et al. 1998). However, at most locations around the world it is necessary to depend on satellite-based passive sensors. Microwave radiometers on polar-orbit satellites produce fairly accurate instantaneous estimates, but their sparse temporal sampling 
constrains the time/space gridding needed to achieve reasonable random errors in the GPCP data set.

Infrared (IR) radiometers on geosynchronous satellites (geo-IR) provide excellent time and space sampling, but the quantity being sensed (mostly cloud-top temperature) is indirectly connected to precipitation, particularly on the shortest time and space scales, and in extratropical latitudes. A problem that geo-IR data share with most satellite data sets is that the viewing geometry becomes unfavorable near the limb of each satellite's view. This problem can be solved in part at tropical and subtropical latitudes by merging all available geo-IR data, but the issue remains, most acutely at higher latitudes and in cases where the closest geosynchronous satellite is not reporting data. An additional barrier is the need to work with several international partners to obtain administrative permissions, maintain routine data deliveries, and dedicate sufficient computing resources before the use of global. full-resolution geo-IR data can be a reality.

Starting in October 1996 the GPCP set the stage for higher resolution estimates by working with the geosynchronous-satellite operators around the world to collect histograms of geo-IR brightness temperature $\left(\mathrm{T}_{\mathrm{b}}\right)$ on a $1^{\circ} \times 1^{\circ}$ grid covering $40^{\circ} \mathrm{N}-40^{\circ} \mathrm{S}$ at 3 -hourly intervals. The availability of this data set prompted the authors to develop the Threshold-Matched Precipitation Inúx (TMPI) iu estimate precipitation from the 3-hoini geo-IR histograms; described in scetion 2. To complete the global coverage, a technique for estimating precipitation outside of the geoIR coverage using sounding data from polar-orbit satellites was developed, as described in section 3. Together, these form the One-Degree Daily (IDD) dataset, which is a first approach to estimating global daily precipitation at the $1^{\circ} \times 1^{\circ}$ scale strictly from observational data. Figure 1 illustrates how the 1DD is computed. The philosophy is to use statistical parameters from trusted estimates to constrain the overall behavior of the 1DD estimates, and then use the geo-IR and sounder data to determine the day-to-day behavior. In the same vein, the adjustments are computed and applied a month at a time to ensure simplicity and stability. All of the computations in this paper are carried out separately for each grid box (perhaps with some smoothing) unless otherwise stated. Section 4 provides some examples of 1DD-based analysis, while section 5 summarizes validation results. Throughout the paper the reader should keep in mind that the geo-IR and sounder data are responding to clouds, rather than hydrometeors, so there is a substantial algorithmic uncertainty at the finest scales.

\section{TMPI}

The GOES Precipitation Index (GPI; Arkin and Meisner 1987) is one popular IR technique that simply labels all pixels with IR $\mathrm{T}_{\mathrm{b}}$ below a threshold as "rain" and assigns a single rainrate to all such pixels. The GPI threshold $T_{b}$ is $T_{b}($ rain $)=235 \mathrm{~K}$ and the conditional rain rate is $R_{c}=3 \mathrm{~mm}$ $\mathrm{h}^{-1}$. These constants were chosen to maximize correlations with half-monthly rainfall on a $2.5^{\circ} \times 2.5^{\circ}$ lat/long grid over the Global Atmosphere Research Program (GARP) Atlantic Tropical Experiment (GATE) ship array in summer 1974. Adler et al. (1993) held $\mathrm{T}_{b}$ (rain) constant and allowed $R_{c}$ to vary according to calibration between (approximately) time/space-matched GPI and SSM/I-based rain estimates accumulated for a month, creating the Adjusted GPI (AGPI). In this paper we introduce the TMPI, which allows both $T_{b}\left(\right.$ rain) and $R_{c}$ to vary. For simplicity and stability, the (spatially varying) $\mathrm{T}_{b}\left(\right.$ rain) and $R_{c}$ are computed on a monthly basis in the TMPI.

The (observational) datasets used for the TMPI (Fig. 1) at present are as follows: 
1. GPCP histograms of geo-IR $\mathrm{T}_{b}$ are compiled on a $1^{\circ} \mathrm{X} 1^{\circ}$ lat/long grid over $40^{\circ} \mathrm{N}-40^{\circ} \mathrm{S}$ at 3 -hr intervals. The histograms have 24 classes covering 190-270K.

2. GPCP Advanced Very High Resolution Radiometer (AVHRR) low-earth-orbit IR (leo-IR) GPI estimates are compiled on a $1^{\circ} \times 1^{\circ}$ lat/long grid over $40^{\circ} \mathrm{N}-40^{\circ} \mathrm{S}$ in 3 -hr averages.

3. The Special Sensor Microwave/Imager (SSM/I) occurrence of precipitation according to the Version 4.0 Goddard Profiling algorithm (GPROF 4.0; Kummerow et al. 1996) is computed by the Goddard Space Flight Center Laboratory for Atmospheres on a $0.5^{\circ} \times 0.5^{\circ}$ lat/long global grid for each orbit. GPROF is a physically based retrieval that matches observed radiances from all $7 \mathrm{SSM} / \mathrm{I}$ channels to cloud-model-based radiances, producing pixel-bypixel precipitation estimates.

4. The GPCP Version 2 Satellite-Gauge (SG; Huffman et al. 1997) combination precipitation estimates $\left(r_{S G}\right)$ are produced on a $2.5^{\circ} \times 2.5^{\circ}$ lat/long global grid by month, and boxinterpolated to $1^{\circ} \times 1^{\circ}$ for this study. The $S G$ applies a sequential combination technique to SSM/I, geo-IR, TOVS (introduced below), and rain gauge analyses

After the geo-IR histograms are corrected for zenith angle effects (Joyce et al. 2000) and interpolated to a $1 \mathrm{~K}$ interval (Joyce and Arkin 1997). they are matched within $\pm 1.5 \mathrm{hr}$ to the microwave-based frequency of precipitation and each is accumulated for the month. To further cnsure stability, the monthly matched accumulations are smocthed with a $7 \times 7$-gridbox boxcar. In each gridbox, the geo-IR histogram is summed starting with the coldest bin until the cumulative fraction of total pixels matches the microwave-based fractional coverage, and $T_{b}$ (rain) is set to the corresponding $T_{b}$. This $T_{b}$ (rain) is applied to the $7 \times 7$-box-smoothed sum of all $T_{b}$ histograms in the box for the month, yielding the fractional occurrence of rain in the full geo-IR dataset for the month, $f_{I R}$. The single local conditional rainrate for all raining pixels is computed as

$R_{c}=\frac{r_{S G}}{f_{I R}}$

because we require the TMPI to sum to the (monthly) SG product over the month to maintain consistency between daily and monthly products.

Preliminary work showed that the $T_{b}$ (rain) and $R_{c}$ computed in this first round of estimation contain some unrealistic values. Various combinations of parameters were tested for diagnosing this problem, of which the plot of $R_{c}$ as a function of $T_{b}$ (rain) seemed the most useful. Not that most points are tightly clustered (Fig. 2), but there is a scatter of high- $R_{c}$ outliers. Outliers usually occur in coherent patches (i.e., inside the red lines on Fig. 3 for the sample month January 1998) that tend to be associated with light rain or strong gradients in rain amount, likely due to sampling problems in the SSM/I data. Such values would tend to cause estimation of a few unrealistically heavy precipitation events during the month. Accordingly, an audit procedure was developed that determines new $\mathrm{T}_{\mathrm{b}}$ (rain) that are consistent with the $\mathrm{SG}$ values, when required. We lack a definitive theoretical basis for identifying outliers, so we have subjectively chosen a linear cutoff that parallels the main cluster and excludes the highest $10 \%$ of boxes for the example month (Fig. 2). At this level of approximation we have neglected the hints at nonlinear behavior for low $T_{b}$ (rain). The outlier $R_{c}$ values are deleted and the pockets of missing are smoothly filled from the surrounding values (Fig. 3). The "audited" values are used to generate audited $f$ and then $\mathrm{T}_{\mathrm{b}}$ (rain) estimates. As shown in Fig. 3, the resulting audited fields are physically reasonable. Small errors in setting these parameters are likely not crucial, since the 
smoothing due to $1^{\circ} \times 1^{\circ}$ gridding and daily summation will mask the detailed pixel-level occurrence of rain. The auditing procedure always reduces $\mathrm{R}_{\mathrm{c}}$ and increases $\mathrm{T}_{\mathrm{b}}(\mathrm{rain})$ and $f$ (except for $T_{b}($ rain $\left.)=269 \mathrm{~K}\right)$.

Even this auditing cannot solve all problems at $T_{b}($ rain $)=269 \mathrm{~K}$ because the warmest $T_{b}$ bin in the merged geo-IR dataset contains all values $\geq 270 \mathrm{~K}$. A region with low cloud-tops, such as a subtropical high, likely should have $T_{b}$ (rain) $\geq 270 \mathrm{~K}$, but $T_{b}$ (rain) must limited to the last distinguishable temperature bin of $269 \mathrm{~K}$ (the uniform orange areas in Fig. 3), and will be given an artificially high $R_{c}$ in the first round of estimation. Presently the auditing procedure replaces $R_{c}$ outliers by (lower) smooth-filled values, even though $T_{b}$ (rain) is constrained to $269 \mathrm{~K}$. This prevents unreasonable instantaneous values at the cost of failing to sum to the monthly SG value. The penalty for this choice is small because nearly all cases are in low-precipitation regions. Note that the corresponding lower limit of the histogram bins $(190 \mathrm{~K})$ is not a problem in practice.

The final audited $R_{c}$ and $T_{b}$ (rain) fields (Fig. 2) provide important insights into the systematic regional variations in geo-IR data. $R_{c}$ and $T_{b}$ (rain) are near the GPI values in tropical oceanic zones with "heavy" precipitation, but the corresponding land areas show much colder $\mathrm{T}_{b}$ (rain) with higher $R_{c}$. This implies that heavy convection in tropical land areas is deeper and more concentrated than over tropical oceans. In the relatively dry subtropical highs $T_{b}($ rain) is warm because there is little or no penetrative convection. The relatively low $T_{b}($ rain $)$ and $R_{c}$ over the Sahara Desert help screen out non-precipitating cirrus that passes over this region during the boreal winter. The gradients along the northern coast of Africa reflect the transition from desert to the pattern of boreal wintertime storms that typifies the Mediterranean.

Holes occur in individual geo-IR images, most routinely in the Indian Ocean sector, where no geo-IR data were available until June 1998. To compensate, leo-IR estimates are processed to fill in holes as necessary. The leo-IR data are only available as GPI estimates in the GPCP merged IR dataset. Therefore, the instantaneous leo-IR estimate for the TMPI is simply the instantaneous leo-IR GPI value scaled by the ratio of the SG for the month to the sum of all leoIR GPI values in the grid box for the month. The adjustment ratios are limited to the range $[0,2.5]$ to ensure reasonable behavior, but this limitation only becomes important in areas of light rain.

The basic output of the TMPI is 3-hrly instantaneous estimates, mostly resulting from geoIR. In the current release, the 3 -hrly images in each UTC day $(00 Z, \ldots, 21 \mathrm{Z})$ are summed to produce the daily value. The daily product is considered more reliable than individual 3-hrly images for two reasons. First, GPI-type IR estimates show better correlation with precipitation as the averaging period increases (Arkin and Meisner 1987). Second, the current procedure does not take into account the time of day (i.e., diurnal cycle biases). As a result, the individual 3-hrly: estimates are not part of the current release.

One interesting result of the TMPI procedure is insight into the frequency of occurrence of precipitation. If we define " fractional coverage " as the fraction of all satellite pixels contributing to the gridbox that have non-zero rain, and "rain days" as the fraction of days on which a gridbox has non-zero rain (i.e., at least one pixel with non-zero rain sometime during the day), then we expect the fractional coverage to be less than rain days. In the case of the TMPI, the ratio of fractional coverage to rain days is less than 0.4 almost every where (Fig. 4). Furthermore, TMPI and GPI rain day maps are closer to each other than to the rain days 
apparently implied by summing GPROF over a day. Thus, "low" (instantaneous pixel-level) fractional coverage is consistent with "high" (day-average gridbox-level) rain days. This implies that the "low" GPROF rain days values are the result of poor time sampling, usually 1 or 2 samples in a day, rather than indicating that the GPROF fractional coverage is unrealistically low. Comparing Figs. 3 and 4, the results also verify that TMPI rain days are higher (lower) than GPI rain days for the TMPI threshold above (below) the GPI $\mathrm{T}_{b}$ (rain) of $235 \mathrm{~K}$.

We find that the instantaneous TMPI fields show good temporal and spatial consistency among images, and with the daily TMPI field (Fig. 5). As we expect, the daily fields are smoother, broader, and have lower maxima than the instantaneous fields. Tests show that the daily TMPI correctly sum to the monthly SG, except in the subtropical North Pacific, where threshold saturation becomes serious for this particular month. We also note that monthly sums of GPROF have significant differences from monthly sums of the TMPI (i.e., the SG field; not shown), demonstrating that the GPROF fractional occurrence can be used to formulate the TMPI without GPROF precipitation rates somehow affecting the computation.

\section{Rescaled Daily TOVS}

Outside the latitude band covered by the merged IR dataset $\left(40^{\circ} \mathrm{N}-40^{\circ} \mathrm{S}\right)$ it is necessary to base the IDV on a different dataset. We selected the Susskind et al. (199\%) precipitation estimates, which are based on Television Infrared Operational Satellite (TIROS) Operational Vertical Sounder (TOVS) data. The original Susskind et al. (1997) precipitation algorithm is a regression between TOVS-based cloud parameters and surface data stratified by latitude, month, and land/ocean surface type. The result is instantaneous pixel-by-pixel precipitation estimates. The choice of the TOVS precipitation was based on global coverage, reasonable performance, and the authors' previous experience with monthly accumulations of this product in developing the GPCP Version 2 SG product. The TOVS precipitation algorithm developers provided the TOVS estimates as daily averages on $1^{\circ} \times 1^{\circ}$ global grid. However, we find that the number of rain days in TOVS is systematically high compared to the TMPI for all months and locations. As well, we wish to ensure that the daily values outside $40^{\circ} \mathrm{N}-40^{\circ} \mathrm{S}$ sum to the monthly GPCP SG.

As a first solution to these issues, we reduce the number of TOVS rain days in a month at each gridbox as follows: We compute the ratio of the zonal average number of TMPI rain days in the month to the same for TOVS separately for $39^{\circ}-40^{\circ} \mathrm{N}$ and $39^{\circ}-40^{\circ} \mathrm{S}$. Then the number of TOVS rain days for the month at each point in an entire hemisphere is scaled by the corresponding ratio (i.e., $39^{\circ}-40^{\circ} \mathrm{N}$ for the Northern Hemisphere). We achieve this smaller number of rain days (in the month for the gridbox) by zeroing the smallest rain accumulations (Fig. 6). The largest daily rain amount to be zeroed is labeled as the "revised zero point." The remaining rain days are linearly rescaled to sum to the monthly SG.

The resulting revised TOVS estimates show good agreement with the TMPI across the $40^{\circ} \mathrm{N}$ and $40^{\circ} \mathrm{S}$ data boundaries. However, enough discrepancy remained on daily maps that smoothing is performed at the boundaries. Specifically, on each day the differences between TMPI and revised TOVS estimates are computed for each of the $39-40^{\circ} \mathrm{N}$ and $39-40^{\circ} \mathrm{S}$ grid boxes, then the difference fields are linearly tapered to zero at $50^{\circ} \mathrm{N}$ and $50^{\circ} \mathrm{S}$, respectively, and added to the revised TOVS. Some spurious "feathering" occurs near the edge of the TMPI domain, but the general effect is beneficial. 


\section{Examples}

The 1DD has been computed for 1 January 1997 - 30 April 1999, and new months continue to be appended a few months after real time. The days 1-2 January 1998 (Fig. 7) are typical of the estimates. Activity in the tropical Pacific reflects the significant El Niño in progress at the time. Note the smooth day-to-day progression of the storm system across the North Pacific. The black dots at high latitudes denote missing data in the original TOVS, mostly due to distortions in the grid at those latitudes.

Focussing on a particular event, Fig. 8 shows the progression of hurricane Mitch in late 1998 . [Note that the color bar scale covers twice the range of that in Fig. 7.] This storm moved northwest in the western Caribbean, then stalled just offshore of northern Honduras. Mitch lost strength as it meandered across western Honduras, but a remnant circulation wandered westnorthwest and emerged in the Bay of Campeche. It rejuvenated to Tropical Storm status. moved quickly northeast across Florida and became extratropical. This dataset allows the events reported on land to be seen in the context of the storm's complete rain production. Individual daily totals were consistent with values for other tropical storms, but the slow forward speed, looping path, and orographic focussing promoted severe flooding across Honduras and Nicaragua.

The 1DD is particularly useful for forming regional/temporal averages of the user's choosing. For example, the Indian Monsoon is summarized in Fig. 9, which displays Hovmoller diagrams for $1997-1998$ of daily precipitation averaged over $85-95^{\circ} \mathrm{E}$ (roughly the span of the Bay of Bengal) displayed for the band $30^{\circ} \mathrm{N}-30^{\circ} \mathrm{S}$. For 1DD (Fig. 9, left panel), the main envelop of precipitation broadens from the Equatorial Indian Ocean (just west of Indonesia) to include the Bay of Bengal in late boreal spring and then retreats six months later, following the annual march of the Sun. The figure shows spectacular, short-lived precipitation events due to averaging over a relatively small area. Careful inspection of Fig. 9 shows that the contours tend to be tilted toward the lower right, indicating that many events move south to north, occasionally from well south of the Equator (e.g., see May in both 1997 and 1998). For comparison with the observed data (Fig. 9, left panel), similarly processed NCEP Reanalysis estimates (Kalnay et al. 1996) are shown in the right panel of Fig. 9. There is fair agreement, even at the daily scale. The NCEP Reanalysis tends to have more widespread light precipitation than the 1DD, and somewhat lower peak values. As a result, the 1DD distinguishes more clearly between active and break periods in the summer. Such differences are qualitatively consistent with the performance that the authors have seen in the Reanalysis, but the quantitative implication depends on further research.

\section{Validation}

An initial validation was carried out over Oklahoma for the period January 1997 - December 1998 for the 1DD using the Oklahoma Mesonet rain gauge data. Mesonet data were used as the validation because the network is fairly dense and none of the stations contributes to the monthly scaling carried out in the $1 D D$. Figure 10 shows the signal to noise ratio (shading) and reference numbers for the $1^{\circ} \times 1^{\circ}$ boxes over Oklahoma. A higher signal to noise ratio indicates there is less error in the Mesonet estimate associated with that box (Morrissey and Greene 1998). This information was used to delete boxes 4 and 7 as having insufficiently robust estimates for gridbox values. For brevity, single-box results are displayed for Box 20, except as noted. 
A plot of the 1DD (solid line, black squares) and Mesonet (dashed line, gray diamonds) daily precipitation over the first six months of 1997 (Fig. 11) is representative of the time series plots over the entire two year period of record. The two time series are clearly related, with dry and wet periods showing agreement. Over the entire 1997-1998 record the correlation coefficient for Box 20 is 0.73 . Looking more closely, the histograms of daily precipitation amounts for the 1DD and Mesonet accumulated from the two years of data are very similar (Fig. 12). The IDD has about $7 \%$ more rain days than the Mesonet, with the excess days spread fairly evenly across the range of precipitation amounts. At the seasonal time scale the results are similar to Fig. 12, with Spring (March-April-May; MAM) and Fall (September-October-November; SON) showing excellent agreement between 1DD and Mesonet, while Summer (June-July-August; JJA) and Winter (December-January-February; DJF) vary somewhat more.

The scatter plots for the Summer and Winter seasons (Fig. 13) reveal a higher correlation during Winter than during Summer. The scatter plots also show fewer outliers during Winter than during Summer. Each scatter plot includes the best-fit line (heavy solid), the associated linear equation, and the $\mathrm{R}^{2}$ value. Note that the days for which both the Mesonet and IDD estimates equaled zero were not removed from the scatter plots, which results in a cluster of points at the origin, tends to tie the best-fit line to the origin. The light dotted line is the one-toone line. In both seasons the best fit shows the 1DD overestimating large precipitation values, with a stronger overestimation in Summer. Tire intercept of the best-fit line is ciose to zero in both seasons, although of opposite sign.

The bias (defined as the 1DD mean divided by the Mesonet mean) and mean absolute error were produced for each 3-month period for each box. The zero-zero points were not removed from the bias calculation, while they were removed from the calculation of the mean absolute error. The bias plot (Fig. 14, top) reveals a semi-annual fluctuation, with underestimation during the Spring and Fall, and nearly unbiased values during the Summer and Winter. Since the 1DD is scaled to the monthly SG, and since SG values are dominated by the gauge analysis in most land areas, it appears that there are systematic differences between the Mesonet and GPCC gauge analyses. The mean absolute error plot (Fig. 14, middle) has a strong maximum during the late Summer season and a minimum during the Winter season. Such variation could result from changes in the character of the precipitation. Specifically, for a fixed set of gauge sites, stratiform precipitation characteristic of the cool season typically yields more accurate area averages, while the warm season's convective precipitation is harder to correctly observe because convection usually has smaller spatial scales. Non-precipitating cirrus is a year-round problem for the IR-based TMPI; in the cool (stratiform) season the principal problem is frontal bands, while in the warm (convective) season it is transient convective anvils. Variations in error could also result from changes in the mean precipitation because precipitation errors tend to scale with mean precipitation amount (Huffman 1997). In the present case Summer convection and maximum average observed (Mesonet) precipitation (Fig. 14, bottom) reinforce each other, leading to the strong annual cycle in mean absolute error. Future work will focus on the relative importance of changes in precipitation type and mean precipitation rate.

Looking more broadly, we computed the average of the 13 box correlation coefficients for each season, as well as the entire record, and compared them to the seasonal and annual correlation coefficients of the 13-box average daily rainfall values (Table 1). As expected, the area averaging improves the correlations significantly, in the range of $15 \%$. Spring and Summer show the greatest improvement, implying that box-to-box fluctuations are larger in those seasons, consistent with a higher incidence of convective activity. 


\section{Concluding Remarks}

The One-Degree Daily (IDD) precipitation estimation technique is a complete firstgeneration scheme for estimating global daily precipitation on a $1^{\circ} \times 1^{\circ}$ grid. The algorithm contains two parts; the Threshold-Matched Precipitation Index (TMPI) over the latitude band $40^{\circ} \mathrm{N}-40^{\circ} \mathrm{S}$ based on a merged geo-IR dataset with leo-IR fill-in, and a rescaled TOVS at higher latitudes based on the Susskind et al. (1997) TOVS precipitation estimates. Both are designed to sum to the GPCP Version 2 monthly Satellite-Gauge combination. The TMPI reflects the frequency of precipitation occurrence computed from SSM/I, while precipitation occurrence in the rescaled TOVS is adjusted to the TMPI at $40^{\circ} \mathrm{N}$ and $40^{\circ} \mathrm{S}$ separately. The 1DD has been computed for 1 January 1997-30 April 1999, and additional months are being computed a few months after real time. The time series of global images show strong continuity from day to day and across the $40^{\circ} \mathrm{N}$ and $40^{\circ} \mathrm{S}$ data boundaries. Initial validation studies show that RMS errors are relatively large, as one would expect from cloud-based methods at fine time and space scales. On the other hand, users should see better accuracy if they time- and/or space-average the IDD fields according to their own requirements.

Further development of the 1DD is expected to take a number of directions. First, we expect to work toward releasing individual 3-hrly estimates, although there will be gaps in individuai fields at higher latitudes. The major issue in this effort is the importance of the time lag between precipitation and cloud-based estimators. Second, estimates based on low-orbit microwave data will be combined directly into the present scheme. This might include Special Sensor Microwave/Imager, Tropical Rainfall Measuring Mission (TRMM) Microwave Imager, and Advanced Microwave Sounding Radiometer data. Third, other sensor systems will be examined for inclusion, including daily gauge data. The last suffers significant difficulties in coverage and time-of-report diversity. Finally, we expect to evaluate more-sophisticated IR and TOVS algorithms for possible improvements in accuracy.

\section{Acknowledgements}

This research was funded through the TRMM Science Team under the NASA Headquarters TRMM Program Scientist Dr. Ramesh Kakar. David Bolvin is thanked for thoughtful reviews. 


\section{References}

Adler, R.F., G.J. Huffman, and P.R. Keehn 1994: Global rain estimates from microwaveadjusted geosynchronous IR data. Remote Sens. Rev., 11, 125-152.

Arkin, P.A., and B. N. Meisner, 1987: The relationship between large-scale convective rainfall and cold cloud over the Western Hemisphere during 1982-1984. Mon. Wea. Rev., 115, 5174.

Blackmon, M.L., Y.H. Lee, J.M. Wallace, and H.H. Hsu, 1984: Time variation of $500 \mathrm{mb}$ height fluctuations with long, intermediate and short time scales as deduced from lag-correlation statistics. J. Atmos. Sci, 41, 981-991.

Crum, T.D., R.E. Saffle, and J.W. Wilson, 1998: An update on the NEXRAD Program and future WSR-88D support to operations. Wea. And Forecasting, 13. 253-262.

Huffman, G.J.. 1997: Estimates of Root-Mean-Square Random Error for Finite Samples of Estimated Precipitation. J. Appl. Meteor., 36, 1191-1201.

Huffman, G.J., R.F. Adler, P. Arkin, A. Chang, R. Ferraro, A. Gruber, J. Janowiak, A. McNab, B. Rudolf, and U. Schneider, 1997: The Global Precipitation Climatology Project (GPCP) Combined Precipitation Data Set. Bull. Amer. Meteor. Soc., 78, 5-20.

Joyce, R.J., and P.A. Arkin, 1997: Improved estimates of tropical and subtropical precipitation using the GOES Precipitation Index. J. Atmos. Oceanic Technol., 10. 304-325.

juyce, R.j., j.E. Jalıwiak, anù G.J. Huiffman, 2000: Latitudinal and seasonal dependent zenith angle corrections for geostationary satellite IR brightness temperatures. J. Appl. Meteor., submitted.

Kalnay, E., M. Kanamitsu, R. Kistler, W. Collins, D. Deaven, L. Gandin. M. Iredell, S. Saha, G. White, J. Woollen, Y. Zhu, M. Chelliah, W. Ebisuzaki, W. Higgins, J. Janowiak, K.C. Mo, C. Ropelewski, J. Wang, A. Leetmaa, R. Reynolds, R. Jenne, and D. Joseph, 1996: The NCEP/NCAR 40-year reanalysis project. Bull. Amer. Meteor. Soc., 77, 437-471.

Kummerow, C., W.S. Olsen, and L. Giglio, 1996: A simplified scheme for obtaining precipitation and vertical hydrometeor profiles from passive microwave sensors. IEEE Trans. Geosci. Remote Sens., 34, 1213-1232.

Morrissey, M.L., and J. S. Green, 1991: The Pacific Atoll Raingauge Data Set. Planetary Geosci. Div. Contrib. 648, Univ. of Hawaii, Honolulu, HI, 45 pp.

Morrissey, M.L., and J.S. Greene, 1998: Using the Oklahoma Mesonet to develop and test a practical sampling error statistic for meteorological time series. J. Geo. Res. 103, 8979-8984.

Susskind, J. P. Pirano, L. Rokke, L. Iredell, and A. Mehta, 1997: Characteristics of the TOVS Pathfinder Path A dataset. Bull. Amer. Meteor. Soc., 78, 1449-1472.

WCRP, 1986: Report of the workshop on global large scale precipitation data sets for the World Climate Research Programme, WCP-111, WMO/TD-No. 94, 45 pp. [Available from World Meteorological Organization, P.O. Box 2300, CH-1211 Geneva 2, Switzerland.] 


\section{List of Tables}

1. Average over $131^{\circ} \times 1^{\circ}$ latitude boxes covering most of Oklahoma (all numbered boxes except 4 and 7 in Fig. 10) of correlation coefficient between daily Mesonet precipitation analyses and 1DD precipitation estimates for the seasons and the total dataset, the rootmean-square difference among the 13 correlation coefficients in each average, and the seasonal and annual correlation coefficients for daily values averaged over the same 13 boxes. 


\section{List of Figures}

1. Block diagram of the $1 D D$ algorithm. The data flow for computing coefficients is shown with solid lines, while production data flow is shown with dashed lines. Gridded data fields are shaded, and the output fields are shown as boxes with heavy borders.

2. Scattergram of the TMPI $R_{c}$ vs. $T_{b}$ (rain) for January 1998 before any auditing is performed. The solid line defines the boundary between outliers and acceptable values (above and below the line, respectively).

3. Audited $\mathrm{T}_{b}$ (rain) in $\mathrm{K}$ (top), and audited $\mathrm{R}_{\mathrm{c}}$ in $\mathrm{mm} \mathrm{hr}^{-1}$ (bottom) for the January $1998 \mathrm{TMPI}$. Blacked-out areas have no data due to a lack of geo-IR data. Red lines enclose areas that have been audited.

4. Occurrence of rain as represented by the TMPI $f_{\text {rain }}$ (top), TMPI rain days (upper middle), GPI rain days (lower middle), and GPROF rain days (bottom) in \% for January 1998.

5. Instantaneous $00 \mathrm{Z}$ (top) and $12 \mathrm{Z}$ (middle) TMPI, and daily TMPI (bottom) in $\mathrm{mm}^{-1}$ for 1 January 1998. Blacked-out areas have no data.

6. Schematic diagram of revising TOVS by establishing a revised zero point (top) and precipitation rate transformation (bottom).

7. 1DD images for 1-2 January $1998 \mathrm{in} \mathrm{mm} \mathrm{d}^{-1}$ (respectively top, bottom). Blacked-out areas have no data.

8. Bilinearly interpolated 1DD images in $\mathrm{mm} \mathrm{d}^{-1}$ for 23 October -05 November 1998 , illustrating the precipitation associated with Hurricane Mitch. The black X's denote Mitch's $12 \mathrm{Z}$ position on each day for which it was available (storm identity was lost during much of 2-3 November as it traversed southern Mexico into the Bay of Campeche). The lower righthand panel displays the 14-day average, multiplied by 4 to fit the same gray-shade key.

9. Hovmoller diagrams in $\mathrm{mm} \mathrm{d}^{-1}$ of $1 \mathrm{DD}$ (left) and NCEP reanalysis (right) daily data for the period 1 January $1997-31$ December 1998 . The diagram extends over $30^{\circ} \mathrm{S}-30^{\circ} \mathrm{N}$ latitude, and each value is an average over the longitudes $85-95^{\circ} \mathrm{E}$.

10. Locator map of Oklahoma Mesonet stations (dots), $1^{\circ} \times 1^{\circ}$ lat/long grid boxes used in this study (numbered boxes), and signal to noise ratio computed for the Mesonet analyses used in this study (shading).

11. Plot of the 1DD (solid line, black squares) and Mesonet (dashed line, gray diamonds) daily precipitation in $\mathrm{mm} \mathrm{d}^{-1}$ over the first six months of 1997 in box 20 .

12. Histograms of daily precipitation amounts for the 1DD and Mesonet (both as in Fig. 11) accumulated for 1997-1998 in box 20.

13. Scattergrams of daily Mesonet data vs. IDD in $\mathrm{mm}^{-1}$ for box 20 for the December-February Winter (top) and June-August Summer (bottom) seasons. The thin dashed line is the 1:1 line, while the heavy solid line is the best-fit line, whose equation and $\mathrm{R}^{2}$ are also shown.

14. Bias, computed as the ratio of average 1DD to average Mesonet (top); mean absolute error of $1 \mathrm{DD}$ from Mesonet in $\mathrm{mm} \mathrm{d}^{-1}$ (middle); and average Mesonet in $\mathrm{mm} \mathrm{d}^{-1}$ (bottom). All quantities are computed for box 20 as 3-month "climatologies" for the period 1997-1998. 
Table 1. Average over $131^{\circ} \times 1^{\circ}$ latitude boxes covering most of Oklahoma (all numbered boxes except 4 and 7 in Fig. 10) of correlation coefficient between daily Mesonet precipitation analyses and 1DD precipitation estimates for the seasons and the total dataset, the root-mean-square difference among the 13 correlation coefficients in each average, and the seasonal and annual correlation coefficients for daily values averaged over the same 13 boxes.

\begin{tabular}{cccc}
\hline Season & $\begin{array}{c}\text { Box-by-box } \\
\text { correlation } \\
\text { coefficient } \\
\text { averaged over 13 } \\
\text { boxes }\end{array}$ & $\begin{array}{c}\text { RMS of box-by- } \\
\text { box correlation } \\
\text { coefficient } \\
\text { averaged over 13 } \\
\text { boxes }\end{array}$ & $\begin{array}{c}\text { Correlation } \\
\text { coefficient of } \\
\text { 13-box daily } \\
\text { average }\end{array}$ \\
\hline Winter & .669 & .143 & .764 \\
Spring & .752 & .084 & .874 \\
Summer & .594 & .160 & .719 \\
Fall & .695 & .138 & .765 \\
Annual & .681 & .096 & .783 \\
\hline
\end{tabular}



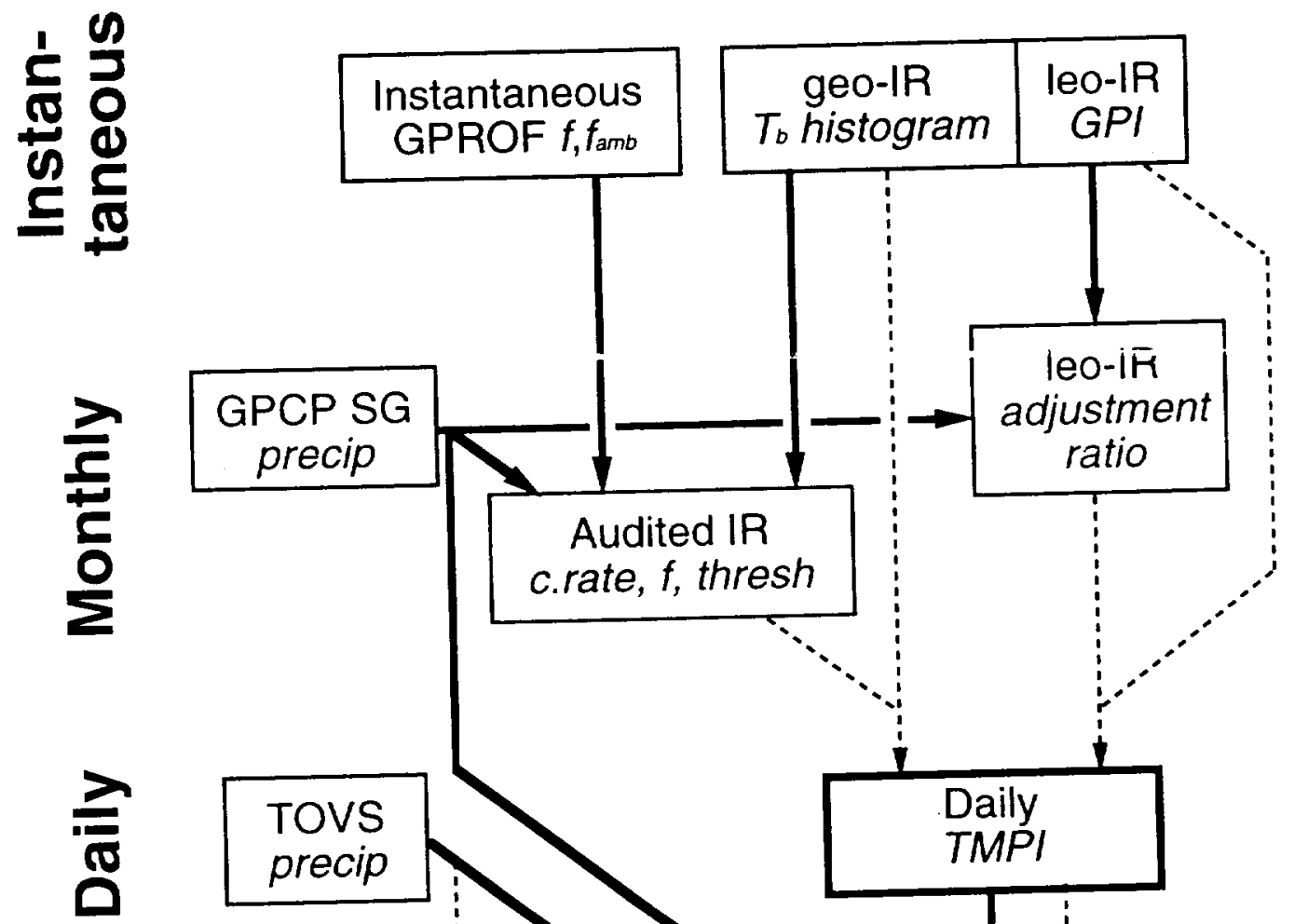

$\frac{\text { a }}{\text { 들 }}$

$\frac{2}{0}$

1DD precip 


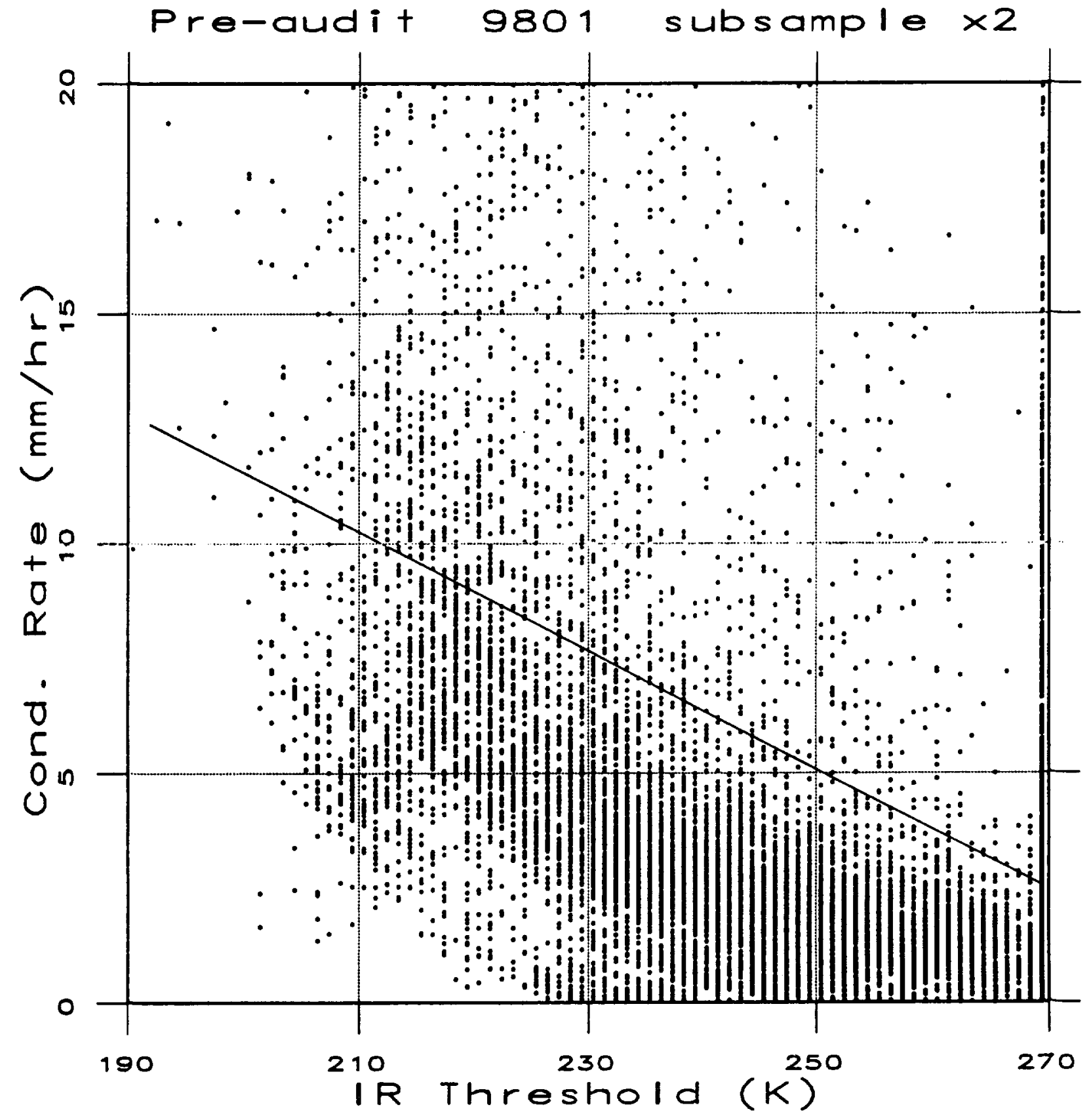

FIGURE 2 


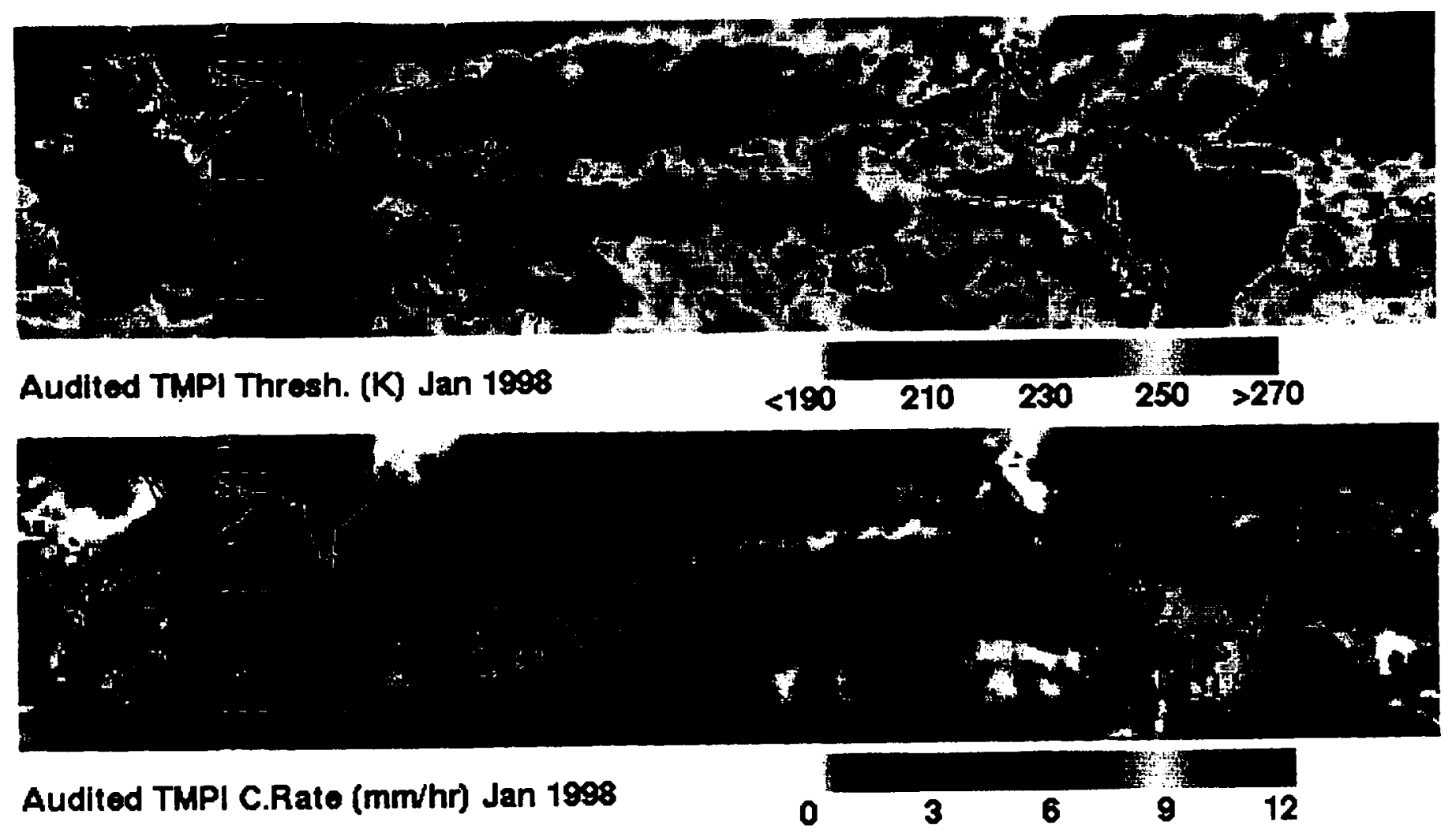

FIGURE 3 

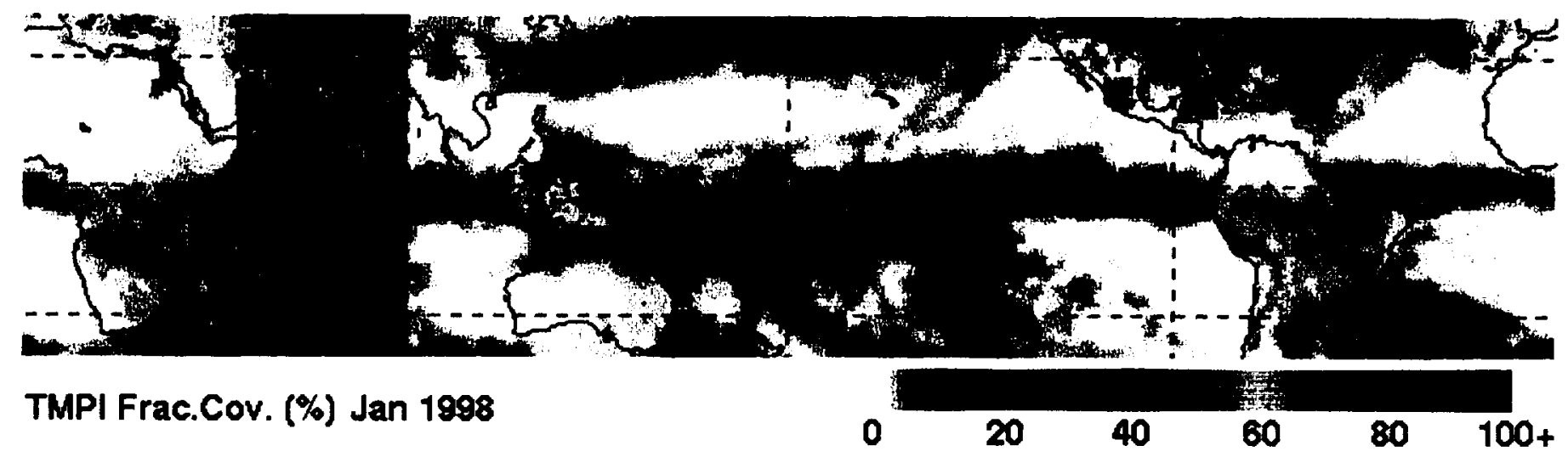

TMPI Frac.Cov. (\%) Jan 1998

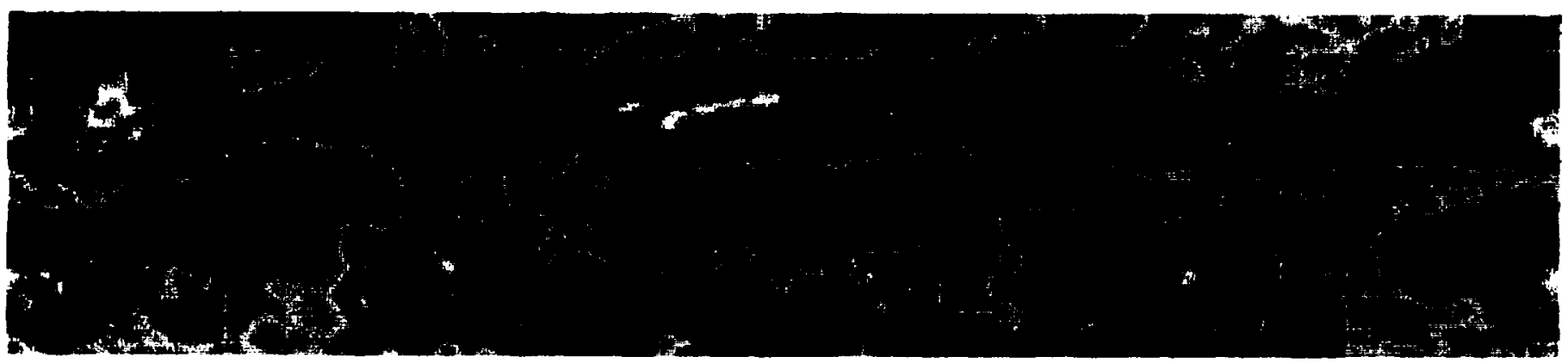

TMPI Rain Days (\%) Jan 1998
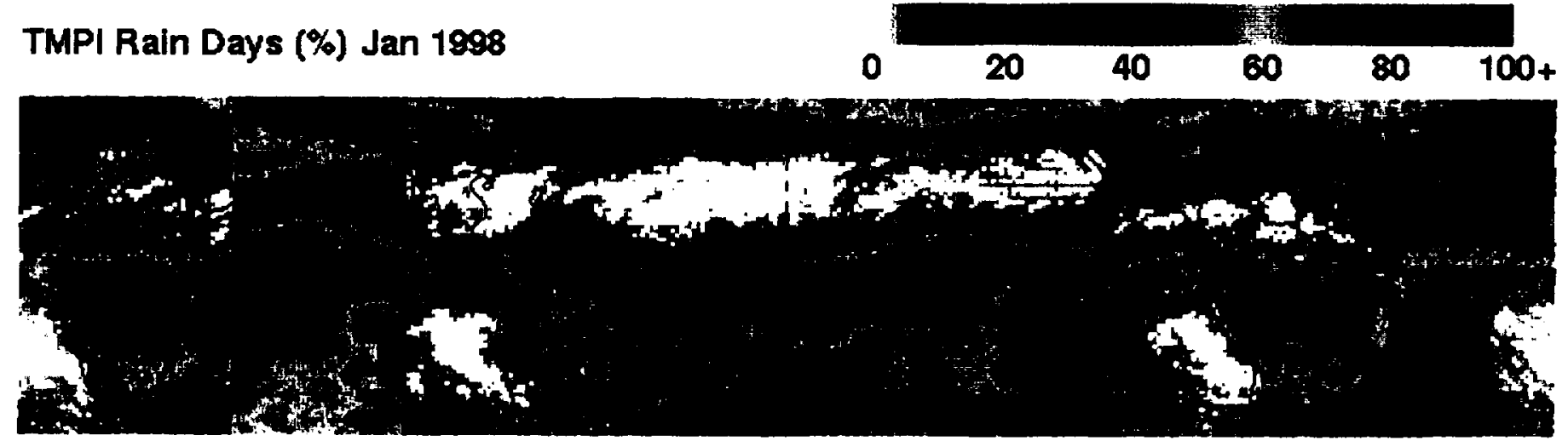

GPI Rain Days (\%) Jan 1998

0

20

40

(4)

60

$80100+$

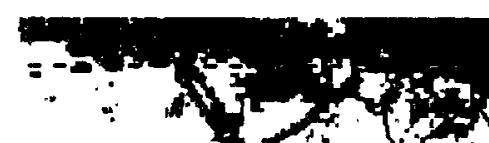

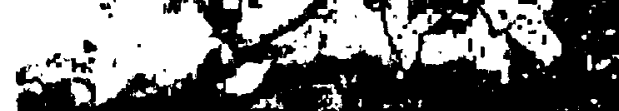

rym

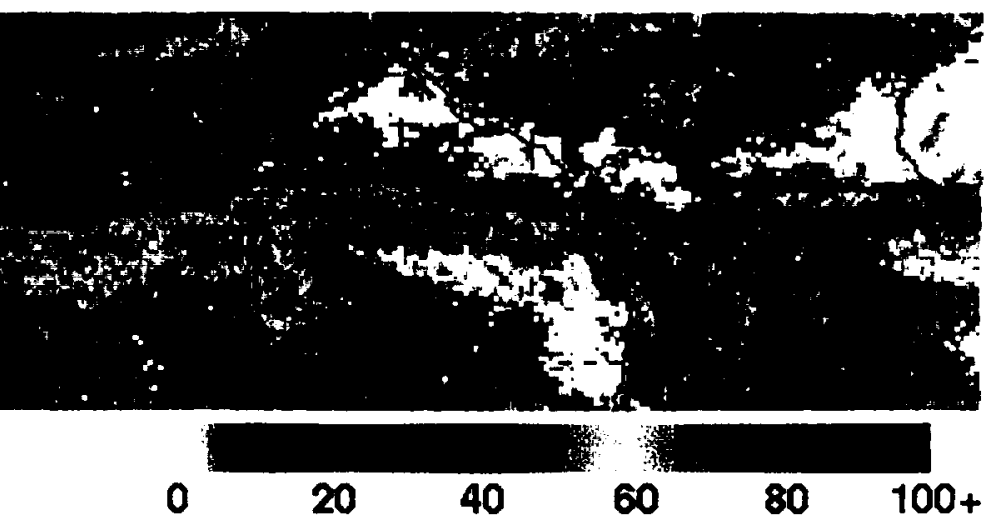
tis

GPROF Rain Days (\%) Jan 1998 


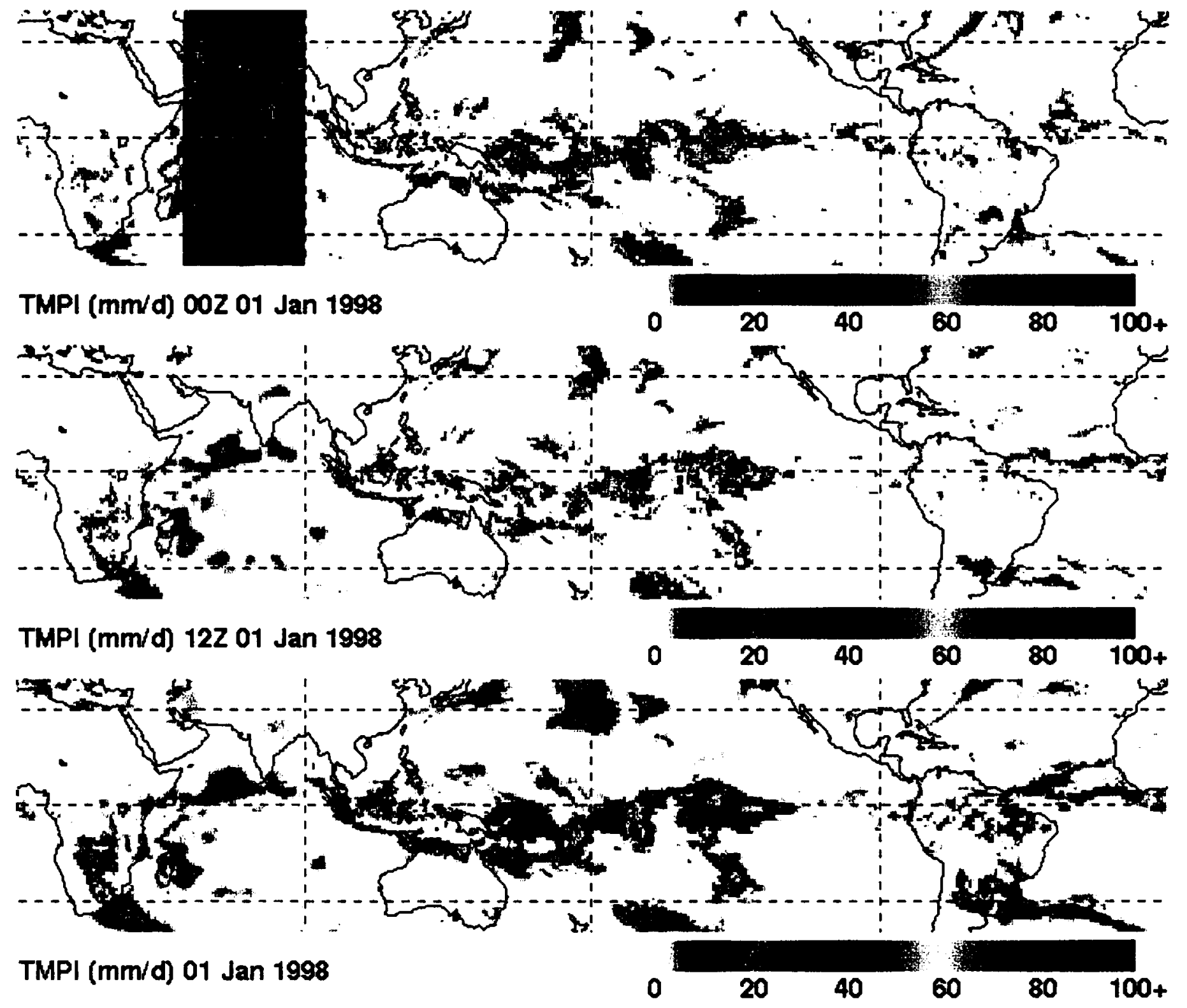




\section{Setting Revised TOVS Zero Point and Rate}
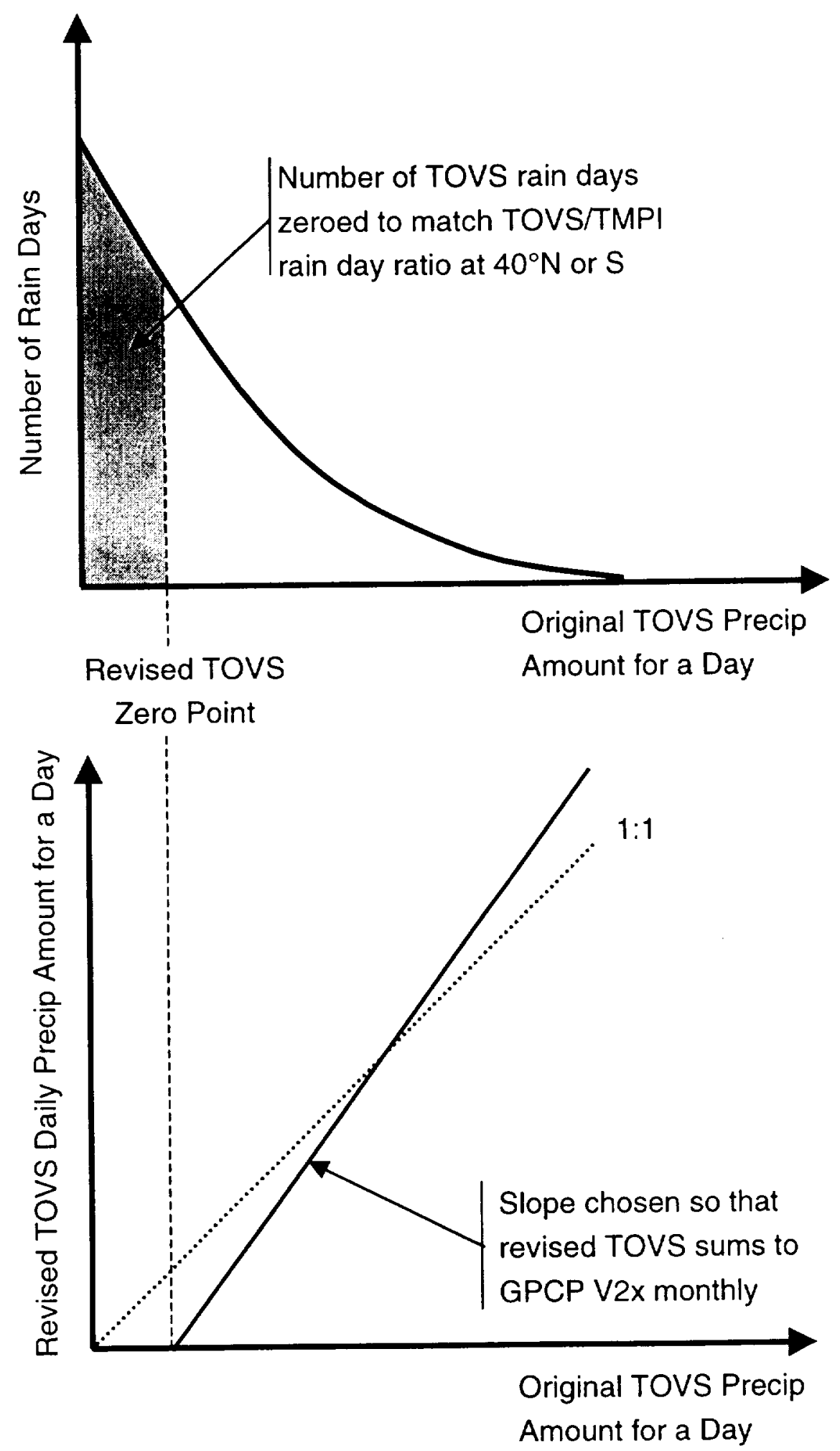

FIGURE 6 


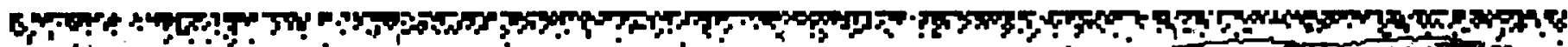
(1)

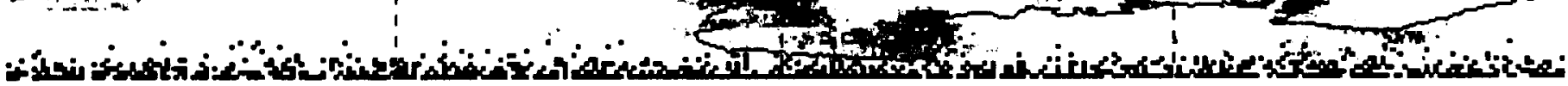
1-Deg Daily (mm/d) 01 Jan 1998 $\begin{array}{llllll}0 & 10 & 20 & 30 & 40 & 50+\end{array}$

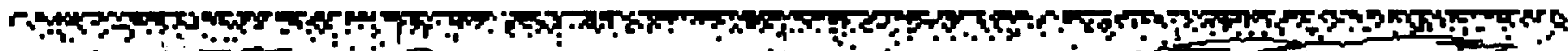

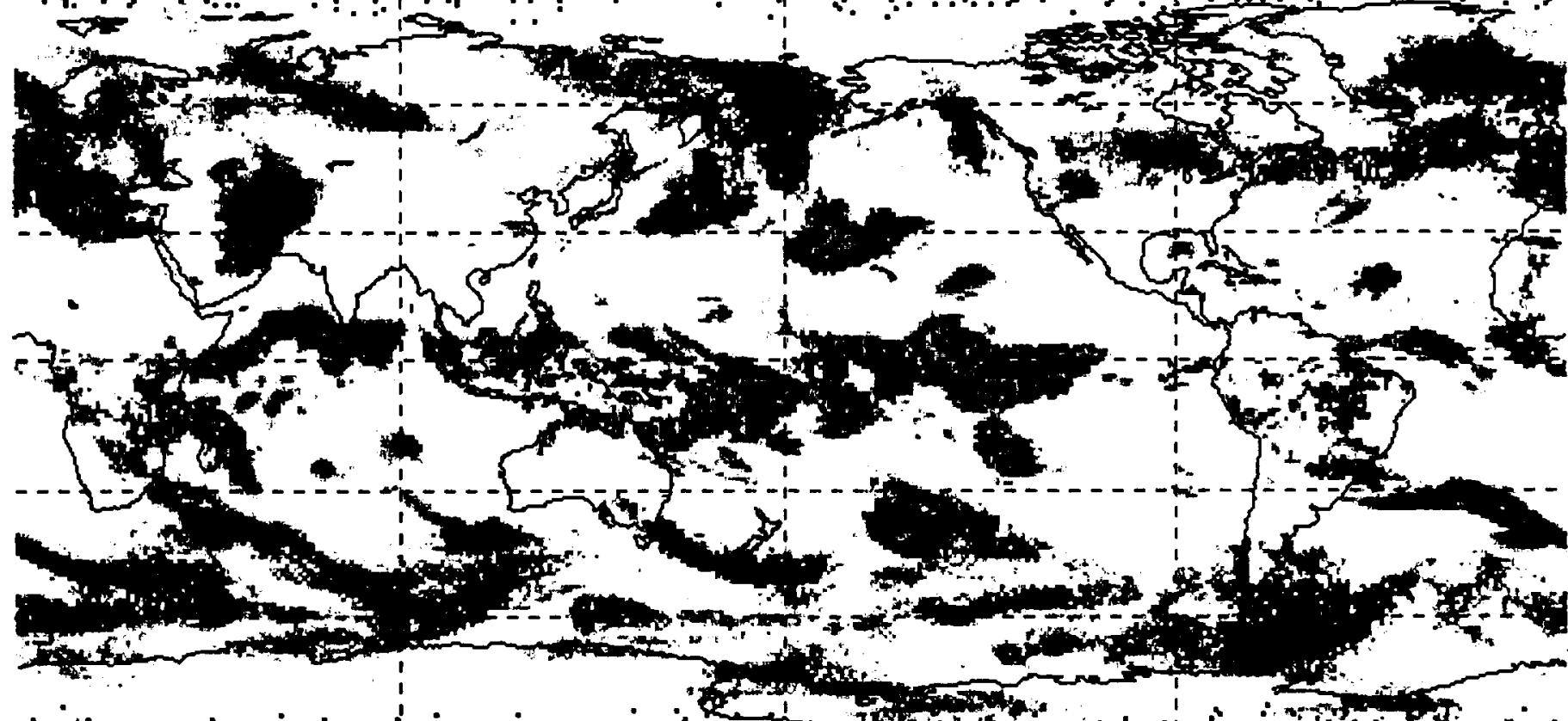

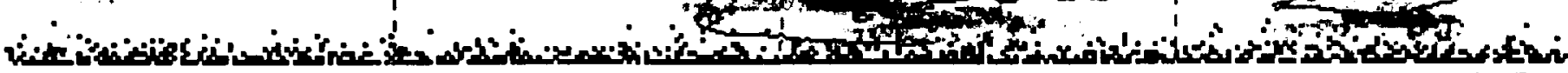
1-Deg Dally (mm/d) ， 02 Jan 1998 

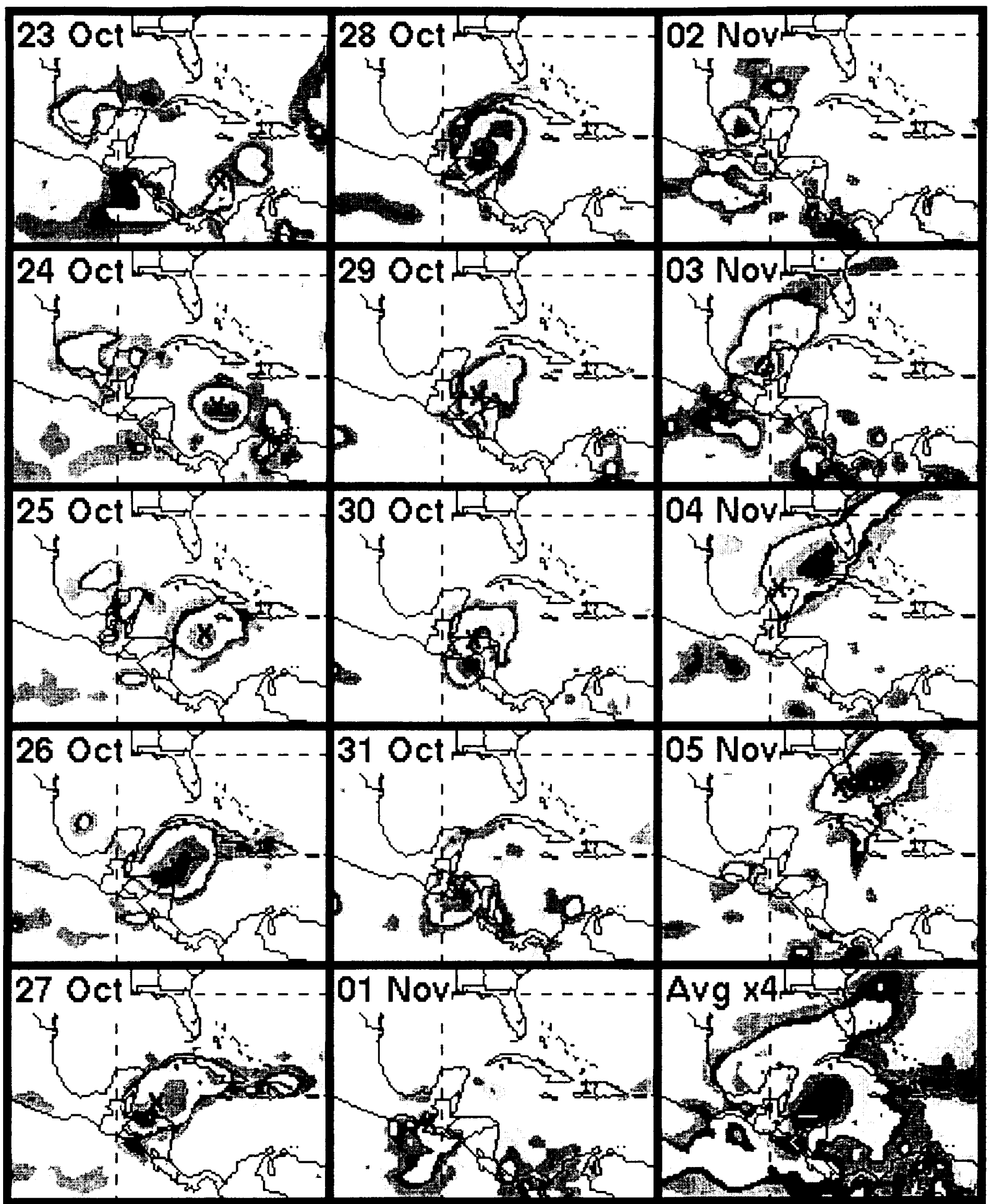

Mitch 1998

1DD $(\mathrm{mm} / \mathrm{d})$

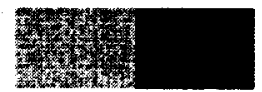

20
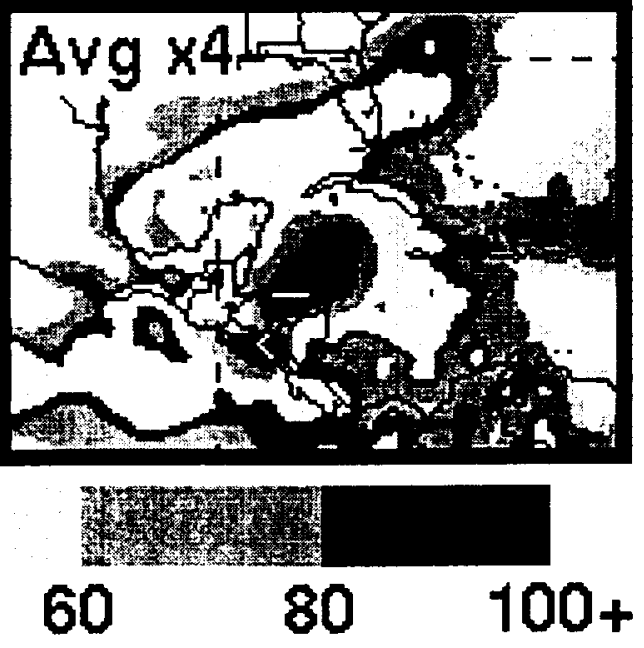


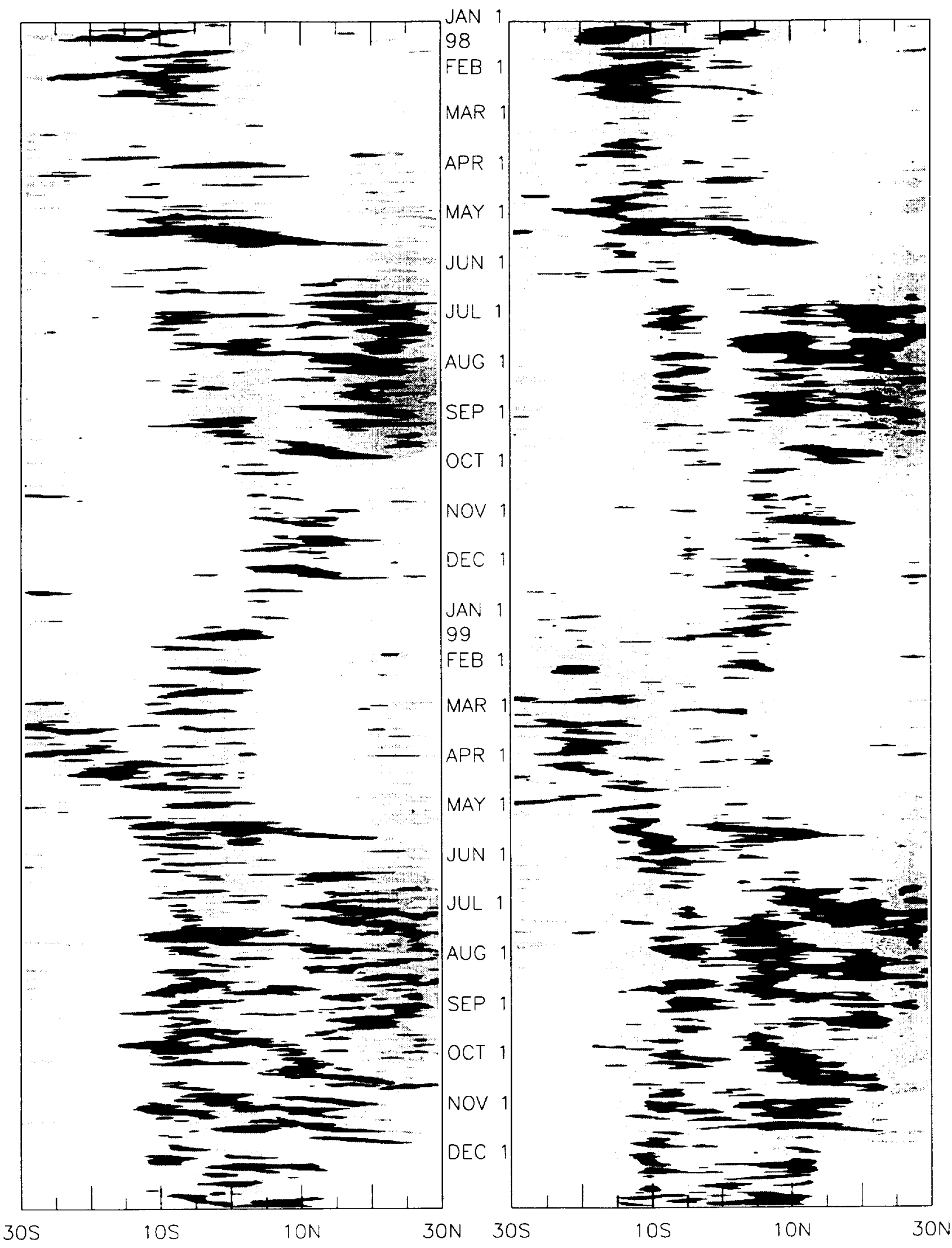
$30 \mathrm{~s}$

HP 


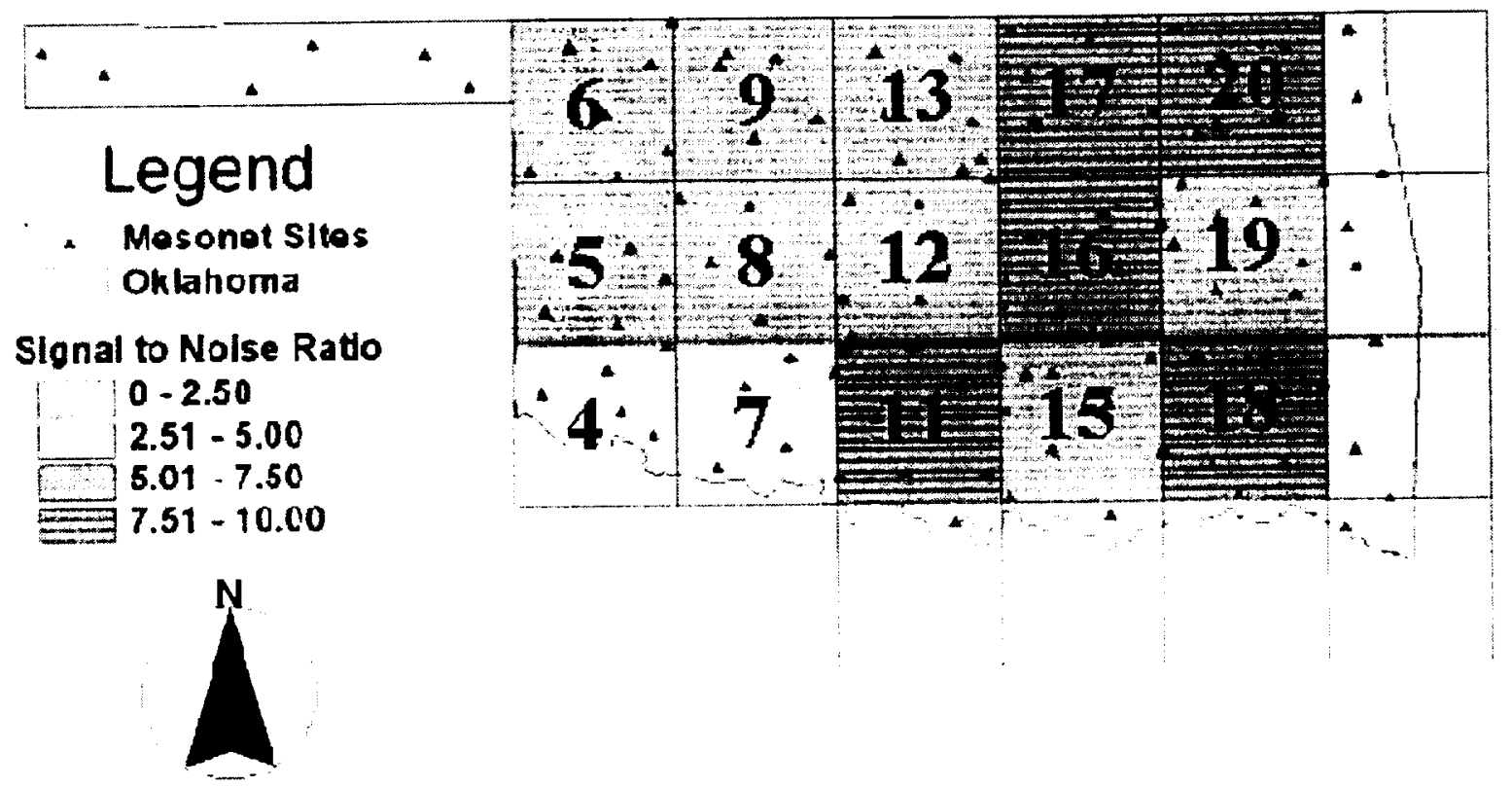




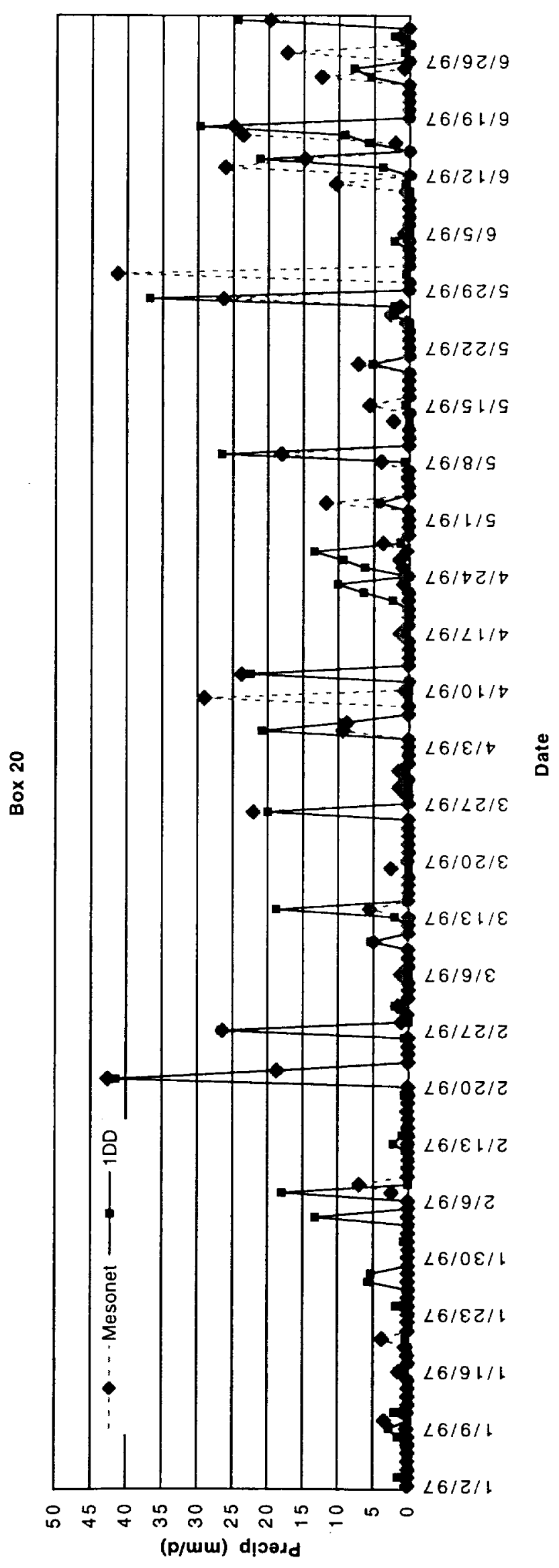

$F$
$\frac{1}{9}$
$\frac{\sigma}{1}$ 


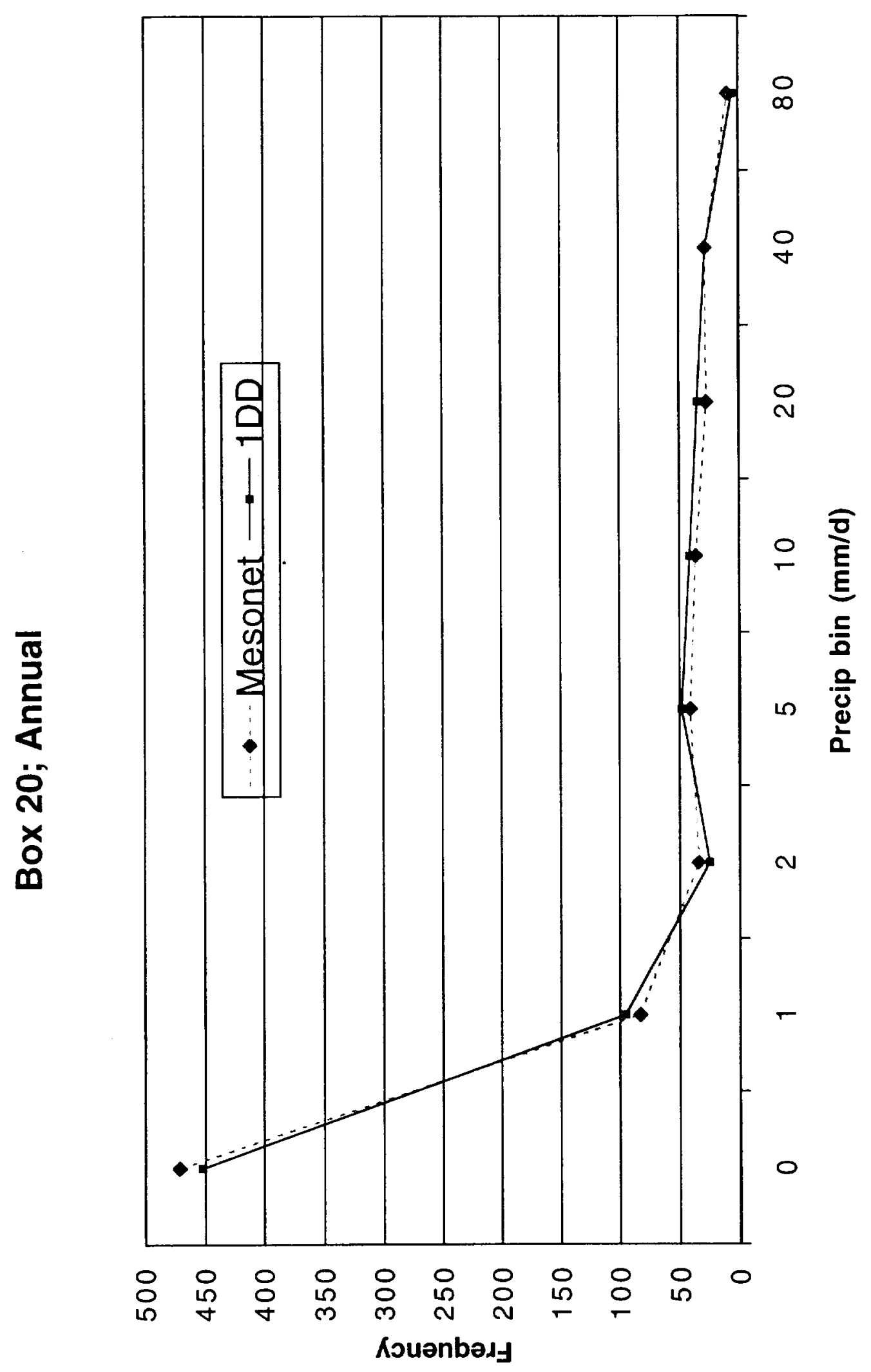

$\frac{N}{w}$
$\frac{\pi}{\sigma}$
$\frac{\sigma}{L}$ 

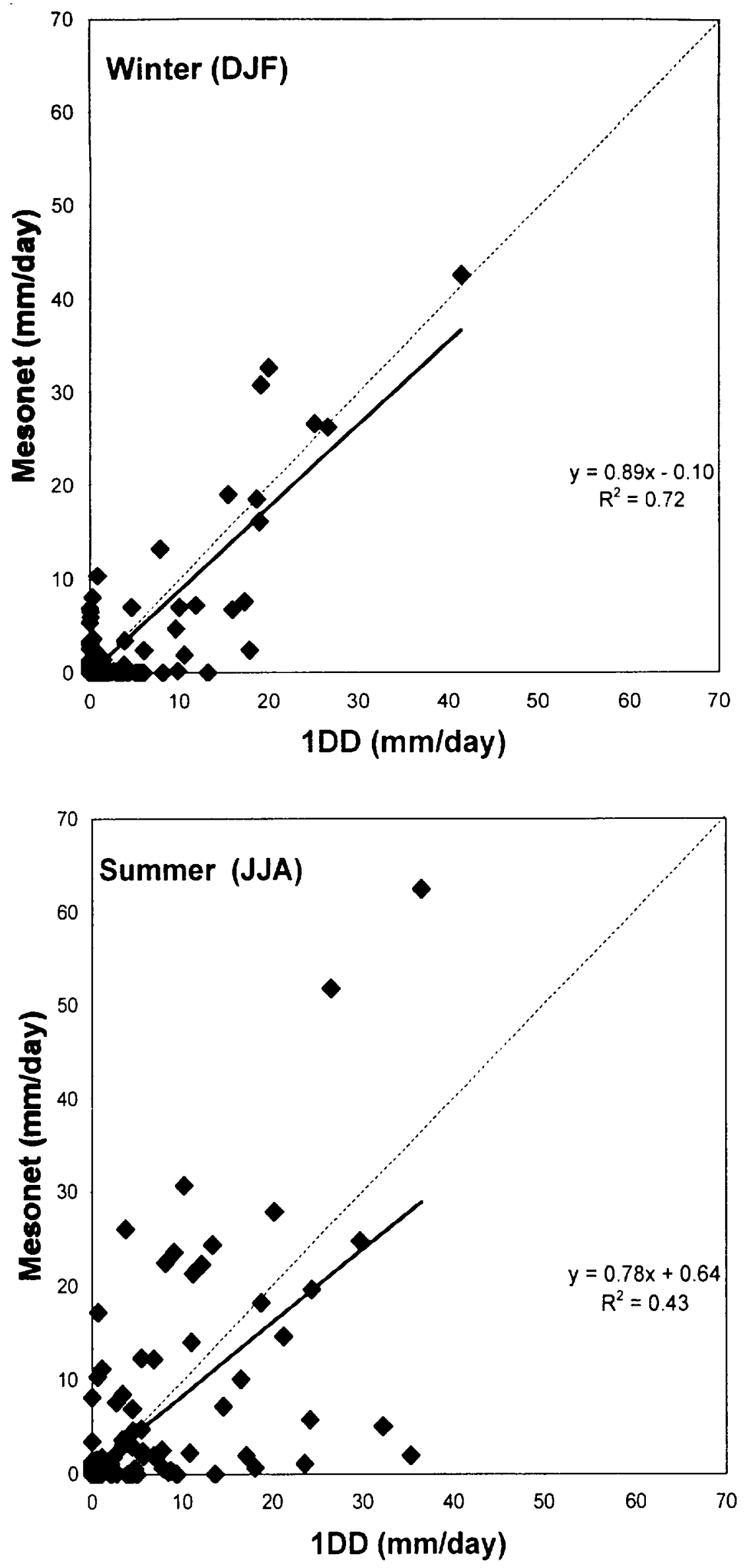

FIGURE 13 

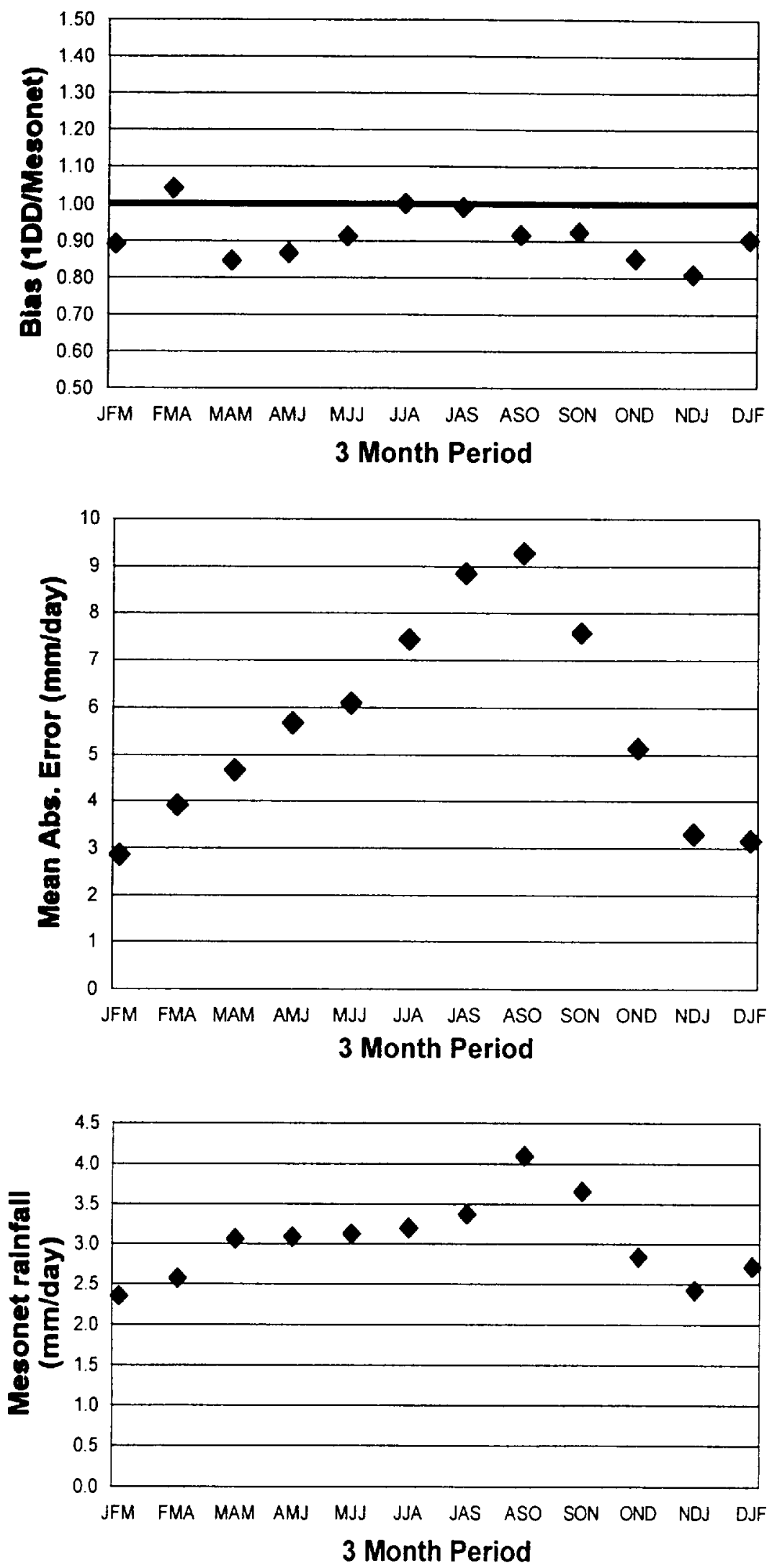

FIGURE 14 